\title{
Anxiety in patients undergoing cataract surgery: a pre- and postoperative comparison
}

\author{
This article was published in the following Dove Press journal: \\ Clinical Ophthalmology \\ 10 November 2017 \\ Number of times this article has been viewed
}

\author{
David A Ramirez ${ }^{1,2}$ \\ Frank L Brodie ${ }^{2}$ \\ Jennifer Rose- \\ Nussbaumer ${ }^{2,3}$ \\ Saraswathy Ramanathan ${ }^{2}$ \\ 'School of Medicine, University of \\ California, San Francisco, ${ }^{2}$ Department \\ of Ophthalmology, University of \\ California, San Francisco, ${ }^{3}$ Francis I. \\ Proctor Foundation, San Francisco, \\ CA, USA
}

Purpose: Reducing surgery-related patient anxiety without under-emphasizing surgical risk is challenging for even the most experienced surgeon. The purpose of this study is to identify specific anxieties faced by patients in hopes of better informing the preoperative surgeon-patient dialogue.

Setting: Comprehensive and specialty ophthalmology clinics at the University of California, San Francisco.

Design: A prospective, survey-based study in which a pre- and postoperative questionnaire was administered to patients undergoing routine phacoemulsification. The surgeon was masked to patient enrollment and questionnaire responses.

Materials and methods: A 36-item questionnaire on patient anxiety was developed from existing literature, building on the validated Surgical Fear Questionnaire. Patients were eligible if they were aged $>18$ years and willing to participate. Patients were excluded if having more than phacoemulsification alone or if unable to respond in English, and were retroactively excluded if there were complications during surgery. The primary outcome was self-reported anxiety on an 11-point Likert scale.

Results: Sixty-one patients were included for analysis. Preoperatively, patients reported greatest anxiety around the operation itself and becoming blind. Reflecting postoperatively, patients reported the greatest anxiety for the operation itself. Statistically significant decreases were greatest for anxiety about the operation failing $(p<0.001)$ and becoming blind $(p<0.001)$. No decrease was observed for the operation itself $(p=0.1)$.

Conclusion: More effort must be made to specifically discuss the steps of the operation itself and the expected visual outcomes to alleviate patient anxiety. The authors hope these data can provide insight for surgeons into patient anxiety surrounding cataract surgery and help strengthen the patient-physician relationship.

Keywords: cataract surgery, patient anxiety, preoperative counseling, informed consent

\section{Introduction}

Preoperative anxiety around cataract surgery affects a large proportion of patients, despite advances in technique and anesthesia administration. ${ }^{1,2}$ Anxiety is a well-known preoperative sentiment, and is present regardless of perceived intrusiveness of the operation. Indeed, one manifestation of this anxiety, the fear of death, predominates patient concerns irrespective of whether the patient undergoes major or minor surgery. ${ }^{3}$ For general surgery patients, concerns regarding anesthesia/pain, complications, and quality of life were common between patients undergoing a major or a minor procedure. ${ }^{4}$ Others have found similar findings before colonoscopy, local skin excisions, and dental procedures. ${ }^{5-7}$ 
Previous ophthalmologic studies have identified anxietyinducing elements specific to cataract surgery, ${ }^{8-11}$ reporting visual sensations and blindness among the major preoperative fears. However, there are few quantitative investigations examining the precise cause of unease in this population. In this study, we examine the sources of preoperative anxiety in patients undergoing routine phacoemulsification cataract surgery both preoperatively and again postoperatively with the goal of informing clinicians so that they can tailor their preoperative counseling to address common concerns.

\section{Materials and methods Study participants}

We prospectively identified consecutive patients undergoing routine phacoemulsification under the care of five attending ophthalmologists at the University of California, San Francisco Medical Center, between September 2016 and January 2017. Patients were included if they were aged $>18$ years, willing to participate in the study, and completed both the pre- and postoperative questionnaire. We excluded patients undergoing multiple procedures during a single operative event (combined cases), those unable to understand or respond in English, and those who had a complication during surgery.

\section{Study design and procedure}

After obtaining verbal informed consent, a preoperative questionnaire was verbally administered to each study participant, either by telephone or in person. Participants rated their anxiety about specific factors related to the surgical process using an 11-point Likert scale, with 0 indicating no anxiety and 10 the maximal amount of anxiety. Participants then rank-ordered their three greatest anxieties using free recall of items from the questionnaire. Postoperatively, participants completed a questionnaire with fields matched to the preoperative questionnaire, asking participants to rate each anxiety as if they were undergoing another operation. Subjects were not permitted to review earlier responses. Surgeons were masked to patient participation and responses.

\section{Survey instrument}

To broadly examine patient anxieties around cataract surgery, our questionnaire evaluated both vision-related and non-vision-related concerns. We adapted questions from the validated Surgical Fear Questionnaire for elective surgery ${ }^{12}$ to correspond to vision and to capture additional anxieties relevant to cataract surgery. We also reviewed previous studies assessing preoperative anxiety from fields with monitored anesthesia care, including interventional cardiology, gynecology, dentistry, local plastic surgery, and minor elective surgery, ${ }^{6,7,13-17}$ as well as general surgery. ${ }^{4,18}$ The final survey instrument contained six demographic questions and 36 anxiety-related questions; Table S1 provides a list of all questions. Cronbach's alpha demonstrated an internal consistency of 0.97 for both the preoperative and postoperative surveys.

\section{Statistical analysis}

We compared demographics stratified by sex using Student's $t$-test or Fisher's exact test, as noted. For our analysis, we used the Shapiro-Wilk test to assess the normality of distribution for each question, and used the paired Wilcoxon rank-sum test to compare pre- and postoperative changes for non-normal distributions. There were 12 subjects completing surveys for each eye, the second of which was excluded from initial analyses given non-independence of the two eyes. However, these subjects were included in our subgroup analysis, which compared those patients who had undergone prior cataract surgery to those presenting for a second cataract surgery. Given a sample size of 61 , based on a two-sided alpha of 0.05 and a power of 0.80 , our minimum detectable change in anxiety was 0.5 . We performed all statistical analyses with $\mathrm{R}$ version 3.3.1 for Macintosh (R Foundation for Statistical Computing, Vienna, Austria, 2016).

The study was approved by the Institutional Review Board at the University of California, San Francisco, and verbal informed consent for participation in the study was obtained from all study subjects. The study adhered to the tenets of the Declaration of Helsinki and the Health Insurance Portability and Accountability Act.

\section{Results}

A total of 199 routine phacoemulsification cases without concurrent surgery were performed during the study period. Of these, 65 (33\%) were done in patients unable to respond in English, 25 (13\%) were in patients unreachable by phone, and $31(16 \%)$ patients declined to participate. Thus, a total of 78 (39\%) surveys were included in the study. Four patients were later excluded for not completing both pre- and postoperative surveys, and one patient had a surgical complication. Twelve patients were surveyed twice due to bilateral surgery, and therefore 61 study participants were included in our analysis. Table 1 summarizes demographic characteristics of the study participants. Fifty two percent of the study participants were women, and the mean age of all participants was $63.9 \pm 13.0$ years. There were no significant differences between sexes for the characteristics shown. 
Table I Participant characteristics, stratified by sex

\begin{tabular}{|c|c|c|}
\hline Characteristics & $\begin{array}{l}\text { Women } \\
(n=29)\end{array}$ & $\begin{array}{l}\text { Men } \\
(n=32)\end{array}$ \\
\hline Age in years $(\text { mean } \pm S D)^{a}$ & $63.6 \pm 12.2$ & $64.1 \pm 13.9$ \\
\hline Previous cataract surgery (\%) ${ }^{\mathrm{b}}$ & 14 & 25 \\
\hline Laterality (\% right eye $)^{\mathrm{b}}$ & 59 & 66 \\
\hline Anxiety diagnosis on problem list (\%) & 10 & 3 \\
\hline
\end{tabular}

Notes: ${ }^{\circledR}$ Nonsignificant difference, Student's t-test. ${ }^{b}$ Nonsignificant difference, Fisher's exact test.

We administered the preoperative survey at a mean of 8 days prior to surgery. Figure 1 shows the top preoperative anxieties (see Table S1 for a list of means, medians, and interquartile range [IQR] for all questions). Preoperative anxiety was highest for the operation itself (median 4, IQR 2-5) and becoming blind (median 3.5, IQR 1-6.25), with each of the remaining six top anxieties in Figure 1 rated a median of 3 . All other questions were rated 2 or below and are not shown.

Figure 2 shows the percentage of patients recalling specific questionnaire items as their top preoperative anxiety. About $19.6 \%$ of patients cited concern about their vision not recovering completely before the operation, and $9 \%$ cited complications during the operation as their primary concern. Despite the operation itself and becoming blind being the highest reported preoperative anxiety-inducing elements in Figure 1, on free recall only $7 \%$ of patients cited these as the most anxiety-inducing preoperatively.

We administered the postoperative survey at a mean of 7 days after surgery. The top anxiety in postoperative responses was the operation itself (median 3, IQR 1-5). Comparing surveys before and after surgery, the majority of responses showed a postoperative decline, with 11 questions demonstrating statistically significant declines, as displayed

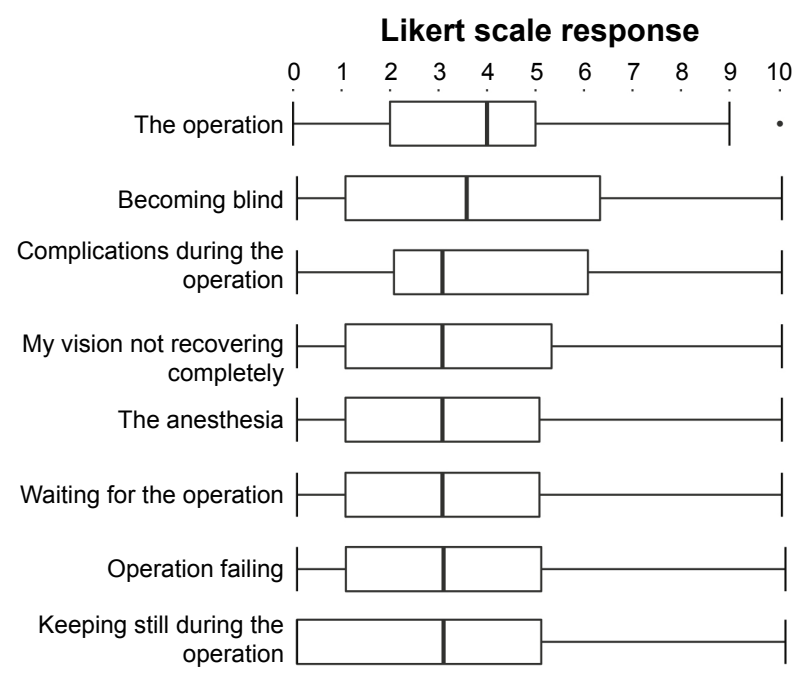

Figure I Box and whisker plot of questionnaire items with the eight highest rated preoperative anxieties.

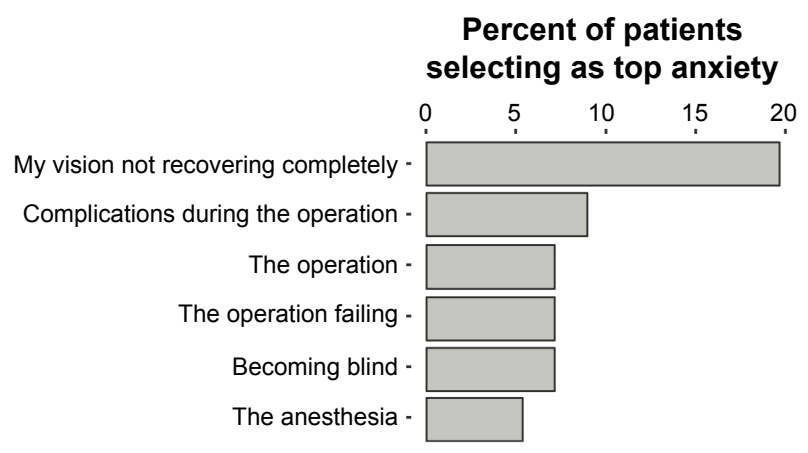

Figure 2 Top anxieties recalled after completion of the preoperative survey; $\mathrm{N}=56$, with five patients citing anxiety due to other factors or declining to rank-order.

in Figure 3. The largest absolute change among these items occurred for anxiety about the operation failing, decreasing by 2 points $(p<0.001)$, and becoming blind, decreasing by 1.5 points $(p<0.001)$. There was no significant decline in anxiety about the operation itself (postoperative median 3, IQR 1-5), the anesthesia (2, IQR 1-5), waiting for the operation (2, IQR 0-6), or keeping still during the operation (1, IQR 0-5). There was a nonsignificant postoperative increase in anxiety around having visual experiences (median increase from 0 to $1, p=0.5$ ) and sedation during the operation (median increase from 0.5 to $1, p=0.9$ ).

In a post hoc analysis, we compared those patients who had not undergone cataract surgery previously to those undergoing an operation for the second eye. In those who had not undergone cataract surgery, anxiety was highest around becoming blind (median 4, IQR 1-7) and the operation itself (median 4, IQR 2-6). For those presenting for the second eye, preoperative anxiety was highest around vision not recovering completely (median 3, IQR 1-5) and complications during the operation (median 3, IQR 1.75-5.25). There was a statistically significant decline in preoperative anxiety between those naïve to cataract surgery and those undergoing a second operation, specifically around the operation itself and concern about not being able to resume a previous lifestyle. Of note, there was a statistically significant increase in anxiety around medical learners being involved in the surgical process (increase from 0 to $2, p=0.04$ ) between the first and second eyes.

We also recorded patient comments during each survey, and selected quotes are shown in Table 2 .

\section{Discussion}

In this study of surgical anxiety among cataract patients, we found that preoperatively, patients have the highest anxiety about the surgical process and surgical outcomes, and few patients were concerned about interactions with 


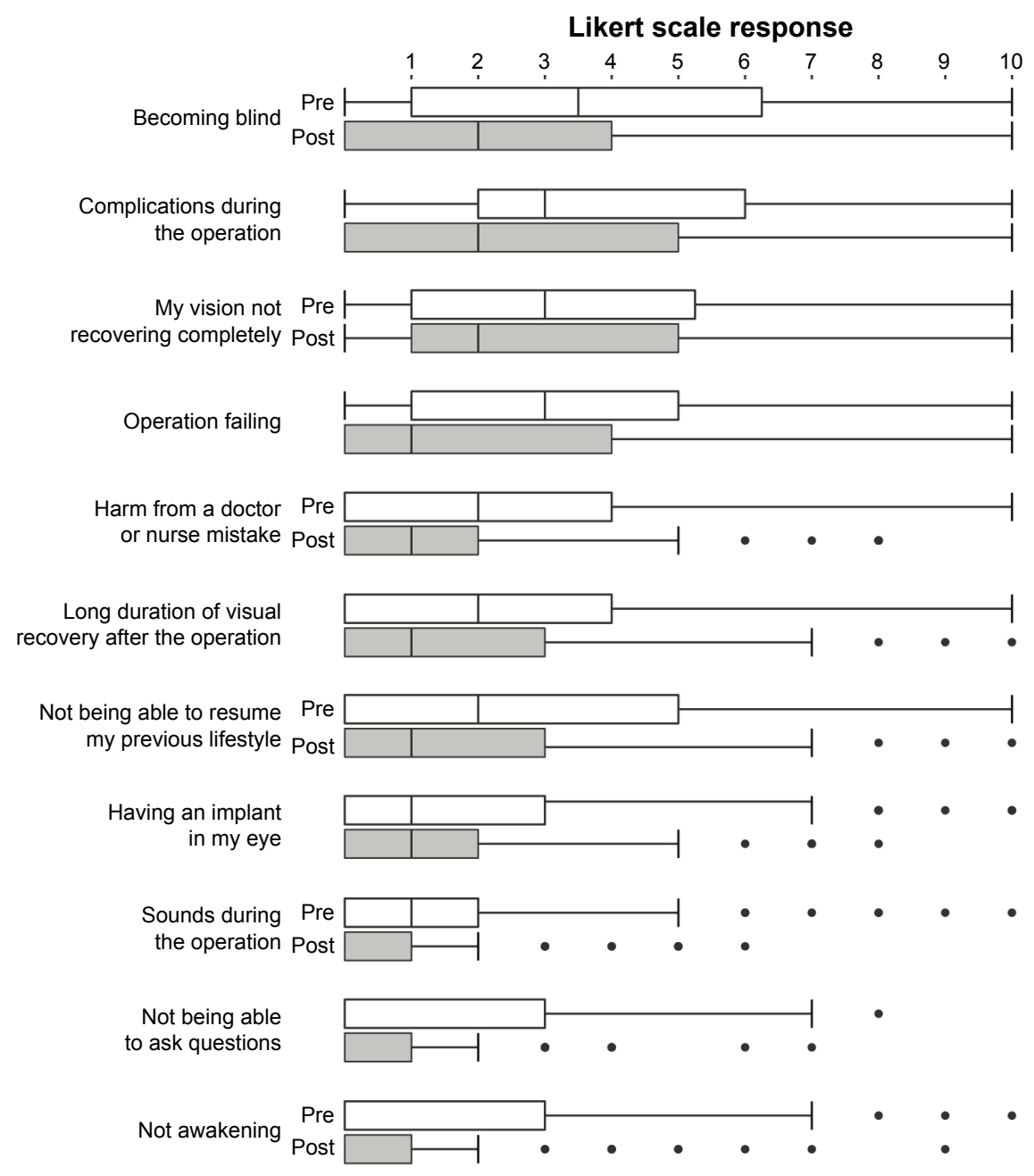

Figure 3 Pre- and postoperative comparisons for questionnaire items demonstrating a statistically significant decline at the postoperative survey $(p<0.05$, Wilcoxon ranksum test).

Table 2 Selected patient quotes per time period

\begin{tabular}{|c|c|c|}
\hline $\begin{array}{l}\text { General } \\
\text { comments }\end{array}$ & $\begin{array}{l}\text { "I've got one eye working } \\
\text { right now and the other is } \\
\text { the old eye. My eyes are off } \\
\text { balance...I didn't anticipate } \\
\text { what it was going to be like } \\
\text { not being able to see." }\end{array}$ & $\begin{array}{l}\text { "I really wasn't [anxious } \\
\text { about the operation } \\
\text { failing] because...I've } \\
\text { heard about several } \\
\text { people having the } \\
\text { same thing done and it } \\
\text { turned out great." }\end{array}$ \\
\hline $\begin{array}{l}\text { Regarding the } \\
\text { operation itself }\end{array}$ & $\begin{array}{l}\text { "Until you had called me...I } \\
\text { hadn't thought about [my } \\
\text { anxiety] very much, but the } \\
\text { questions you asked made } \\
\text { me a little anxious." }\end{array}$ & $\begin{array}{l}\text { "In fact, I found [hearing } \\
\text { voices of operating } \\
\text { room personnel] to be } \\
\text { quite helpful... it gave } \\
\text { me confidence in what } \\
\text { they were doing." }\end{array}$ \\
\hline $\begin{array}{l}\text { Regarding the } \\
\text { anesthesia }\end{array}$ & $\begin{array}{l}\text { “....it hadn't been thoroughly } \\
\text { explained. The options } \\
\text { [the anesthesiologist] } \\
\text { gave me were if you're } \\
\text { uncomfortable then let me } \\
\text { know and we'll give you } \\
\text { something. But I didn't want } \\
\text { to be uncomfortable in the } \\
\text { first place.” }\end{array}$ & $\begin{array}{l}\text { "[We need] a little } \\
\text { more emphasis on the } \\
\text { sedation, not waiting } \\
\text { until someone starts to } \\
\text { hurt, starting it a little } \\
\text { early so you don't have } \\
\text { to go through the initial } \\
\text { 'ouch'." }\end{array}$ \\
\hline
\end{tabular}

the surgical staff. Overall anxiety levels for the majority of items preoperatively were low and further decreased postoperatively, which is consistent with prior reports. ${ }^{2}$

Recognizing the most frequent sources of patient anxiety, we may address those concerns in preoperative discussion with patients, as sharing information is the surgeon's most powerful tool to help alleviate patient anxiety. In both medical and surgical procedures, prior reports have suggested that additional written information and extended discussion may also improve patient comprehension in a clinical setting. ${ }^{19}$ For cataract surgery, preoperative counseling, specifically for visual sensations, has been shown to reduce level of patient fear as well as the proportion of patients reporting any level of anxiety. ${ }^{20,21}$ Therefore, discussing the specifics of anesthesia, details of the location the patient will wait in preparation for the operation, who will attend to their needs during this time, or offering the patient potential solutions, such as surgical tape to assist with keeping the head still during the operation, may lessen the anxiety witnessed in this study. 
In our study, there was a discord between the item causing the highest level of anxiety and the item patients recalled as being their top concern. This could indicate that the necessary discussions incorporating the risks and benefits may not address each patient's specific anxieties. Asking the patient about their principle concerns may aid in the reduction of their anxiety, as each patient approaches the operation with different experiences and perceptions that may not be captured in a standard informed consent.

For the anxieties among the highest rated but demonstrating no significant postoperative decline, incorporation into existing preoperative discussions is imperative. For two such anxieties, namely concern about the operation itself and the anesthesia, the lack of decline could be due to a phenomenon noted previously where patients, having been sedated during the first operation and thus altering their recall ability, expect to be unaware during the second surgery. When this does not meet their expectation, they are more aware and may report greater pain immediately after the operation..$^{22}$ In addition, these particular items can be vague and difficult for patients to grasp, perhaps leading to persistent anxiety. Defining the steps of the operation itself, for example, with a focus on what the patient will see, feel, and hear, rather than on the details of technique, may make the experience more concrete and contribute to reducing patient anxiety. Debriefing about these elements during the intraoperative and postoperative encounters may also help reduce subsequent patient anxiety if another operation is necessary.

Studies on anxiety for cataract surgery largely address general levels of anxiety ${ }^{2}$ or examine a specific fear during surgery, such as visual experiences. ${ }^{11}$ In similar studies in other fields, fear of death predominates preoperative concerns regardless of surgical severity. ${ }^{3}$ Although this finding was not reproduced here, we conceptualize the fear of death as analogous to the fear of becoming blind in ophthalmology patients. The prevalence of fear of blindness could be due to the fact that postoperative complications, such as loss of vision, are discussed as part of the informed consent process. Indeed, the patient quote addressing increasing anxiety levels after survey participation lends weight to the effect of discussion about blindness and complications on patient anxiety.

Increasing anxiety levels after preoperative discussion may occur during the informed consent process, in which the patient and surgeon discuss serious risks of the surgery. This process, which may have been seen in the present study, likely forces the patient to think about potential complications and may aggravate anxiety. While it is important that the patient understand the risks of the operation, they may also benefit from further attempts at anxiety mitigation during that preoperative discussion, as noted earlier. Balancing patient anxiety with the likelihood for complications, however small, remains a delicate act.

In our post hoc subgroup analysis, we found that the highest anxieties were similar to our pooled analysis. However, we did note that for the second surgery, there seemed to be an increase in anxiety about medical learners being involved. One study noted that among patients who did not recall being informed of trainee involvement, there was a higher level of reported dissatisfaction. ${ }^{23}$ Though our participating surgeons included a discussion about involvement of residents during the surgery, this discussion may need to be expanded to align explicitly with intraoperative experience.

Limitations to the generalizability of this study include the small sample size, the university-based setting, and exclusion of non-English speaking patients. Patients unable to respond in English may have anxieties in addition to or apart from the items tested here and warrant separate investigation. Exclusion of patients with complications may have limited the postoperative range of responses; however, given the low complication rate of cataract surgery in general, we feel our findings are generalizable to the overall population of patients undergoing surgery. Furthermore, as complications are generally not predictable, surgeons may find it difficult to provide anticipatory guidance specific to the patient's complication until the postoperative course has been defined. Thus, patients in the preoperative state may still benefit from a discussion of the specific anxieties discussed here. An additional limitation is the impact of anesthetic on patient recall, which may limit the patient's ability to remember specifics about the operation or the anesthesia and thus heighten anxiety.

\section{Conclusion}

Our study offers insight into patient concerns before surgery and how these same concerns are mitigated or remain postoperatively. Anticipating patient anxiety about the intraoperative experience and visual outcomes in the preoperative discussion, and perhaps discussing visual outcomes immediately postoperatively or at the first follow-up visit, may improve overall patient anxiety and improve patient satisfaction. Such discussion may also strengthen the patient-surgeon relationship, which may aid the surgeon in elucidating more candidly the patient's specific concerns. Further investigation into anxieties for non-English speaking patients (for whom anxiety may very well be heightened), as well as an expansion of preoperative counseling to reduce the specific anxieties found here, is warranted. 


\section{Acknowledgments}

This publication was supported by the NIH-National Institute on Minority Health and Health Disparities, grant R25MD006832 (Mr Ramirez), and the National Center for Advancing Translational Sciences, National Institutes of Health, through UCSF-CTSI Grant Number UL1 TR001872. The content of the article is solely the responsibility of the authors and does not necessarily represent the official views of the NIH.

\section{Disclosure}

The authors report no conflicts of interest in this work.

\section{References}

1. Fagerstrom R. Fear of a cataract operation in aged persons. Psychol Rep. 1993;72(3c):1339-1346.

2. Foggitt PS. Anxiety in cataract surgery: pilot study. $J$ Cataract Refract Surg. 2001;27(10):1651-1655.

3. Burkle CM, Mann CE, Steege JR, Stokke JS, Jacob AK, Pasternak JJ. Patient fear of anesthesia complications according to surgical type: potential impact on informed consent for anesthesia: consent for anesthesia. Acta Anaesthesiol Scand. 2014;58(10):1249-1257.

4. Fernandez Lobato RC, Soria-Aledo V, Jover Navalón JM, Calvo Vecino JM. Grupo de trabajo de la Asociación Española de Cirujanos (AEC). National survey on patient's fears before a general surgery procedure. Cir Esp. 2015;93(10):643-650.

5. Chatman N, Sutherland JR, van der Zwan R, Abraham N. A survey of patient understanding and expectations of sedation/anaesthesia for colonoscopy. Anaesth Intensive Care. 2013;41(3):369-373.

6. Caddick J, Jawad S, Southern S, Majumder S. The power of words: sources of anxiety in patients undergoing local anaesthetic plastic surgery. Ann R Coll Surg Engl. 2012;94(2):94-98.

7. Muglali M, Komerik N. Factors related to patients' anxiety before and after oral surgery. J Oral Maxillofac Surg. 2008;66(5):870-877.

8. Nijkamp MD, Ruiter RAC, Roeling M, et al. Factors related to fear in patients undergoing cataract surgery: a qualitative study focusing on factors associated with fear and reassurance among patients who need to undergo cataract surgery. Patient Educ Couns. 2002;47(3):265-272.

9. Nijkamp MD, Kenens CA, Dijker AJM, Ruiter RAC, Hiddema F, Nuijts RMMA. Determinants of surgery related anxiety in cataract patients. Br J Ophthalmol. 2004;88(10):1310-1314.
10. Marback R, Temporini E, Kara Júnior N. Emotional factors prior to cataract surgery. Clin São Paulo Braz. 2007;62(4):433-438.

11. Chaudhry TA, Aqil A, Aziz K, Javed AA, Tauqir MZ, Ahmad K. Patients' visual experience during phacoemulsification cataract surgery and associated fear. BMC Res Notes. 2014;7:663.

12. Theunissen M, Peters ML, Schouten EGW, et al. Validation of the Surgical Fear Questionnaire in adult patients waiting for elective surgery. PLOS ONE. 2014;9(6):e100225.

13. Appukuttan D. Strategies to manage patients with dental anxiety and dental phobia: literature review. Clin Cosmet Investig Dent. 2016;8: $35-50$.

14. Baser E, Togrul C, Ozgu E, Esercan A, Caglar M, Gungor T. Effect of pre-procedural state-trait anxiety on pain perception and discomfort in women undergoing colposcopy for cervical cytological abnormalities. Asian Pac J Cancer Prev. 2013;14(7):4053-4056.

15. Heikkilä J, Paunonen M, Laippala P, Virtanen V. Patients' fears in coronary arteriography. Scand J Caring Sci. 1999;13(1):3-10.

16. Koivula M, Tarkka M-T, Tarkka M, Laippala P, Paunonen-Ilmonen M. Fear and in-hospital social support for coronary artery bypass grafting patients on the day before surgery. Int J Nurs Stud. 2002;39(4): 415-427.

17. Trotter R, Gallagher R, Donoghue J. Anxiety in patients undergoing percutaneous coronary interventions. Heart Lung $J$ Acute Crit Care. 2011;40(3):185-192.

18. Jawaid M, Mushtaq A, Mukhtar S, Khan Z. Preoperative anxiety before elective surgery. Neurosci Riyadh Saudi Arab. 2007;12(2):145-148.

19. Schenker Y, Fernandez A, Sudore R, Schillinger D. Interventions to improve patient comprehension in informed consent for medical and surgical procedures: a systematic review. Med Decis Mak Int J Soc Med Decis Mak. 2011;31(1):151-173.

20. Haripriya A, Tan CSH, Venkatesh R, Aravind S, Dev A, Au Eong K-G. Effect of preoperative counseling on fear from visual sensations during phacoemulsification under topical anesthesia. $J$ Cataract Refract Surg. 2011;37(5):814-818.

21. Voon L-W, Au Eong K-G, Saw S-M, Verma D, Laude A. Effect of preoperative counseling on patient fear from the visual experience during phacoemulsification under topical anesthesia: multicenter randomized clinical trial. J Cataract Refract Surg. 2005;31(10):1966-1969.

22. Ursea R, Feng MT, Zhou M, Lien V, Loeb R. Pain perception in sequential cataract surgery: comparison of first and second procedures. $J$ Cataract Refract Surg. 2011;37(6):1009-1014.

23. Vallance JH, Ahmed M, Dhillon B. Cataract surgery and consent. $J$ Cataract Refract Surg. 2004;30(7):1479-1485. 


\section{Supplementary material}

Table SI Means, medians, and interquartile ranges of all survey question responses, stratified by survey administration relative to the operative period

\begin{tabular}{|c|c|c|c|c|c|c|c|c|c|c|}
\hline \multirow[t]{2}{*}{ "I am anxious about..." } & \multicolumn{5}{|c|}{ Preoperative } & \multicolumn{5}{|c|}{ Postoperative } \\
\hline & $\begin{array}{l}\text { 25th } \\
\text { percentile }\end{array}$ & Median & $\begin{array}{l}\text { 75th } \\
\text { percentile }\end{array}$ & Mean & $\begin{array}{l}\text { Standard } \\
\text { deviation }\end{array}$ & $\begin{array}{l}\text { 25th } \\
\text { percentile }\end{array}$ & Median & $\begin{array}{l}\text { 75th } \\
\text { percentile }\end{array}$ & Mean & $\begin{array}{l}\text { Standard } \\
\text { deviation }\end{array}$ \\
\hline The operation & 2 & 4 & 5 & 3.9 & 3.0 & I & 3 & 5 & 3.4 & 3.0 \\
\hline Becoming blind & I & 3.5 & 6.25 & 3.9 & 3.4 & 0 & 2 & 4 & 2.5 & 3.0 \\
\hline The anesthesia & I & 3 & 5 & 3.4 & 2.9 & I & 2 & 5 & 3.0 & 2.9 \\
\hline Complications during the operation & 2 & 3 & 6 & 4.0 & 3.1 & 0 & 2 & 5 & 2.7 & 2.9 \\
\hline The operation failing & I & 3 & 5 & 3.9 & 3.2 & 0 & I & 4 & 2.4 & 2.8 \\
\hline $\begin{array}{l}\text { My vision not recovering completely } \\
\text { from the operation }\end{array}$ & I & 3 & 5.25 & 4.0 & 3.3 & 1 & 2 & 5 & 3.0 & 3.0 \\
\hline Keeping still during the operation & 0 & 3 & 5 & 3.0 & 3.0 & 0 & I & 5 & 2.8 & 3.1 \\
\hline Waiting for the operation & I & 3 & 5 & 3.2 & 2.8 & 0 & 2 & 6 & 3.2 & 3.1 \\
\hline Complications after the operation & I & 2 & 5 & 3.4 & 3.2 & 0 & 2 & 5 & 2.7 & 2.9 \\
\hline Harm from a doctor or nurse mistake & 0 & 2 & 4 & 2.6 & 3.0 & 0 & 1 & 2 & 1.7 & 2.4 \\
\hline $\begin{array}{l}\text { The long duration of visual recovery } \\
\text { after the operation }\end{array}$ & 0 & 2 & 4 & 3.1 & 3.0 & 0 & 1 & 3 & 2.3 & 2.6 \\
\hline Pain during the operation & 0 & 2 & 5 & 2.9 & 3.1 & 0 & 1 & 4 & 2.7 & 3.2 \\
\hline $\begin{array}{l}\text { Not being able to resume my previous } \\
\text { lifestyle }\end{array}$ & 0 & 2 & 5 & 3.0 & 3.1 & 0 & I & 3 & 2.1 & 2.7 \\
\hline Having awareness during the operation & 0 & I & 4 & 2.2 & 2.9 & 0 & I & 3 & 2.0 & 2.7 \\
\hline My family worrying & 0 & 1 & 4 & 2.2 & 2.5 & 0 & I & 3 & 1.9 & 2.3 \\
\hline Having an implant in my eye & 0 & I & 3 & 2.4 & 3.2 & 0 & I & 2 & 1.6 & 2.2 \\
\hline Pain after the operation & 0 & I & 3 & 1.9 & 2.4 & 0 & I & 4 & 2.3 & 2.8 \\
\hline $\begin{array}{l}\text { The unpleasant side effects (like } \\
\text { nausea) after the operation }\end{array}$ & 0 & 1 & 3 & 1.7 & 2.2 & 0 & 0 & 3 & 1.4 & 2.1 \\
\hline $\begin{array}{l}\text { The sound and vibration of surgical } \\
\text { instruments }\end{array}$ & 0 & I & 2 & 1.7 & 2.5 & 0 & 0 & 1 & 0.9 & 1.6 \\
\hline Needing help at home & 0 & 0.5 & 2.25 & 2.0 & 2.9 & 0 & 0.5 & 3 & 1.7 & 2.4 \\
\hline $\begin{array}{l}\text { Medical learners being involved in } \\
\text { my care }\end{array}$ & 0 & 0.5 & 2.25 & 1.8 & 2.6 & 0 & 0 & 2 & 1.3 & 2.2 \\
\hline Sedation during the operation & 0 & 0.5 & 3 & 1.8 & 2.5 & 0 & I & 3 & 1.9 & 2.6 \\
\hline Death due to the operation & 0 & 0 & I & I.I & 2.0 & 0 & 0 & 2 & 1.3 & 2.2 \\
\hline Fasting for the operation & 0 & 0 & 3 & 1.4 & 1.9 & 0 & 0 & 3 & 1.5 & 2.4 \\
\hline $\begin{array}{l}\text { Not managing postoperative } \\
\text { instructions correctly }\end{array}$ & 0 & 0 & 2 & 1.1 & 1.7 & 0 & 0 & 2 & $\mathrm{I} .4$ & 2.1 \\
\hline Appearing foolish & 0 & 0 & 2 & 1.3 & 2.4 & 0 & 0 & I & 0.8 & 1.6 \\
\hline $\begin{array}{l}\text { My health deteriorating because of the } \\
\text { operation }\end{array}$ & 0 & 0 & 2 & 1.6 & 2.8 & 0 & 0 & 2 & 1.2 & 2.1 \\
\hline $\begin{array}{l}\text { Being at the mercy of the staff, or } \\
\text { feeling helpless }\end{array}$ & 0 & 0 & 2.25 & 1.6 & 2.6 & 0 & 0 & 2 & 1.2 & 1.8 \\
\hline Not being able to ask questions & 0 & 0 & 3 & 1.6 & 2.3 & 0 & 0 & I & 0.8 & 1.6 \\
\hline Not awakening from the operation & 0 & 0 & 3 & 1.7 & 2.6 & 0 & 0 & 1 & 1.0 & 2.1 \\
\hline $\begin{array}{l}\text { The staff having discussions } \\
\text { without me }\end{array}$ & 0 & 0 & 2 & 1.2 & 2.1 & 0 & 0 & I & 0.6 & I.I \\
\hline $\begin{array}{l}\text { Not being able to stop the operation } \\
\text { if needed }\end{array}$ & 0 & 0 & 2 & 1.5 & 2.6 & 0 & 0 & 1 & 1.0 & 1.7 \\
\hline $\begin{array}{l}\text { Being away from home in an unfamiliar } \\
\text { environment }\end{array}$ & 0 & 0 & 2 & I.I & 1.7 & 0 & 0 & 1 & 0.9 & $\mathrm{I} .4$ \\
\hline $\begin{array}{l}\text { Having visual experiences (seeing light } \\
\text { or movement) during the operation }\end{array}$ & 0 & 0 & 3 & 1.7 & 2.5 & 0 & 1 & 3 & 1.6 & 2.2 \\
\hline $\begin{array}{l}\text { Hearing the voices of operating room } \\
\text { personnel during the operation }\end{array}$ & 0 & 0 & 2 & 1.5 & 2.6 & 0 & 0 & 1 & 0.9 & 1.5 \\
\hline Taking time away from work & 0 & 0 & 2 & 1.4 & 2.5 & 0 & 0 & 2 & 1.0 & 1.8 \\
\hline
\end{tabular}




\section{Publish your work in this journal}

Clinical Ophthalmology is an international, peer-reviewed journal covering all subspecialties within ophthalmology. Key topics include: Optometry; Visual science; Pharmacology and drug therapy in eye diseases; Basic Sciences; Primary and Secondary eye care; Patient Safety and Quality of Care Improvements. This journal is indexed on

Submit your manuscript here: http://www.dovepress.com/clinical-ophthalmology-journal
PubMed Central and CAS, and is the official journal of The Society of Clinical Ophthalmology (SCO). The manuscript management system is completely online and includes a very quick and fair peer-review system, which is all easy to use. Visit http://www.dovepress.com/ testimonials.php to read real quotes from published authors. 